\title{
Survei Keterampilan Gerak Dasar pada Siswa Sekolah Menengah Pertama
}

\author{
Merinda Degita Sari*, Siti Nurrochmah \\ Universitas Negeri Malang, Jl. Semarang No. 5 Malang, Jawa Timur, Indonesia \\ *Penulis korespondensi, Surel: merindadegitasari@gmail.com
}

Paper received: 17-6-2021; revised: 1-7-2021; accepted: 8-7-2021

\begin{abstract}
Basic motion skills (locomotor, non locomotor, and manipulative) that have been taught at the elementary school level as the basis for performing more complex motion skills (sports branches) at the junior high school level. However, based on preliminary observations on grade VII students at SMP UM Malang, many students have difficulty doing practice on basic technical skills for running, jumping and jumping during physical education learning and the results of interviews with PJOK teachers obtained information that the teacher had never held a test basic motion skills (locomotor, non locomotor and manipulative motion). The purpose of this research is to obtain and study the ability of students' basic movement skills. This study uses a quantitative descriptive form design with survey methods. The instrument used in the form of tests of basic movement skills and non-forms of observation tests. The collected data were analyzed using quantitative descriptive statistical techniques. The results of the analysis of basic motion skills test data (1) locomotor is included in the good enough category, (2) non locomotor is included in the good enough category, and (3) manipulative is included in the good enough category. The conclusion of the research result is that basic movement skills (locomotor, non locomotor, and manipulative) in class VII students at SMP Laboratorium UM Malang city are categorized as good enough.
\end{abstract}

Keywords: fundamental movement skills; locomotor; nonlocomotor; manipulative

\begin{abstract}
Abstrak
Keterampilan gerak dasar (lokomotor, non lokomotor, dan manipulatif) yang sudah diajarkan pada jenjang pendidikan sekolah dasar (SD) sebagai dasar untuk melakukan keterampilan gerak yang lebih kompleks (cabang olahraga) pada jenjang sekolah menengah pertama (SMP). Namun berdasarkan observasi awal pada siswa kelas VII di SMP laboratorium UM Kota Malang menunjukkan banyak siswa mengalami kesulitan dalam melakukan praktik tentang materi keterampilan teknik dasar lari, loncat dan lompat pada saat pembelajaran pendidikan jasmani dan hasil wawancara dengan guru PJOK didapatkan informasi bahwa guru belum pernah mengadakan tes keterampilan gerak dasar (gerak lokomotor, non lokomotor dan manipulatif). Tujuan penelitian ini memperoleh dan mengkaji kemampuan keterampilan gerak dasar siswa. Penelitian ini menggunakan rancangan bentuk deskriptif kuantitatif dengan metode survei. Instrumen yang digunakan berupa tes bentuk keterampilan gerak dasar dan non-tes bentuk observasi. Data yang terkumpul dianalisis menggunakan teknik statistika deskriptif kuantitatif. Hasil analisis data tes keterampilan gerak dasar (1) lokomotor termasuk dalam kategori cukup baik, (2) nonlokomotor termasuk dalam kategori cukup baik, dan (3) manipulatif termasuk kategori cukup baik. Simpulan hasil penelitian yaitu keterampilan gerak dasar (lokomotor, non lokomotor, dan manipulatif) pada siswa kelas VII di SMP Laboratorium UM tergolong dalam kategori cukup baik.
\end{abstract}

Kata kunci: keterampilan gerak dasar; lokomotor; nonlokomotor; manipulative

\section{Pendahuluan}

Gerak dasar merupakan dasar untuk mempelajari dan mengembangkan suatu keterampilan teknik dalam melakukan berolahraga dan beraktivitas fisik seumur hidup (Bakhtiar, 2015). Berarti gerak dasar merupakan dasar untuk mempelajari dan 
mengembangkan dalam melakukan suatu aktivitas olahraga atau fisik yang lebih kompleks pada kehidupan sehari-hari. Keterampilan gerak dasar memiliki peranan yang penting dalam kegiatan pembelajaran pendidikan jasmani olahraga dan kesehatan, terutama pada cabang olahraga yang menuntut tubuh untuk berpindah tempat. Terkait dengan peranan tersebut, berarti dalam pendidikan jasmani olahraga dan kesehatan materi keterampilan gerak dasar penting diperhatikan dalam kegiatan pembelajaran (Hanief, 2015).

Keterampilan gerak dasar (lokomotor, non lokomotor, dan manipulatif) yang sudah diajarkan pada jenjang pendidikan sekolah dasar (SD) sebagai dasar untuk melakukan keterampilan gerak yang lebih kompleks (cabang olahraga) pada jenjang sekolah menengah pertama (SMP). Hal itu diperkuat dengan hasil yang menunjukkan bahwa keterampilan gerak dasar memberikan kontribusi yang signifikan terhadap keterampilan bermain small-sides handball games (Fadilah \& Wibowo, 2018). Keterampilan gerak dasar memberikan kontribusi yang signifikan terhadap keterampilan gerak dasar (Sepriadi, 2017). Namun pada kenyataanya yang terjadi pada keterampilan gerak dasar yang dimiliki siswa SMP tidak sesuai dengan apa yang diharapkan. Hal itu sejalan dengan hasil yang menunjukkan keterampilan gerak pada siswa putra kelas VII tingkat SLTP di kecamatan Pucanglaban dengan hasil yang menunjukan bahwa siswa putra kelas VIII tingkat SLTP di kecamatan Pucanglaban memiliki keterampilan gerak (motor ability) berkategori kurang sebesar 92,2\% (Buchur, 2018).

Untuk mendukung ketersedian informasi, peneliti melakukan observasi berupa pengamatan awal di lapangan dan wawancara kepada guru PJOK kelas VII di SMP Laboratorium UM Kota Malang. Hasil observasi (pengamatan) menunjukkan bahwa banyak siswa mengalami kesulitan dalam melakukan praktik tentang materi keterampilan teknik dasar lari, loncat dan lompat pada saat mengikuti pembelajaran pendidikan jasmani. Sedangkan hasil wawancara memberikan informasi bahwa di SMP Laboratorium UM Kota Malang belum pernah diadakan tes tentang keterampilan gerak dasar pada siswa kelas VII. Jadi kesimpulannya keterampilan gerak dasar pada siswa masih kurang, oleh karena itu penelitian ini penting dilakukan untuk dapat menunjang keterampilan gerak siswa sehingga siswa dapat melakukan keterampilan gerak yang baik dan benar. Sedangkan untuk guru dapat merencanakan perangkat pembelajaran sehingga tujuan pembelajaran dapat tercapai.

Berhubungan dengan permasalahan tersebut, penelitian tentang masalah "Survei Kemampuan Gerak Dasar Lokomotor, Nonlokomotor dan Manipulatif Siswa Kelas III SD 1 Patokpicis Kecamatan Wajak Kabupaten Malang" memberikan hasil penelitian tingkat keterampilan gerak dasar lokomotor dan nonlokomotor termasuk dalam kriteria baik sedangkan gerak dasar manipulatif pada kriteria sedang (Sidharta, 2017). Sedangkan penelitian tentang "Survei Kemampuan Gerak Lokomotor Pada Siswa Kelas VII SMP Darussalam Kecamatan Kademangan Kabupaten Blitar" dengan hasil bahwa kemampuan gerak lokomotor pada siswa kelompok putra lari 50 meter dengan rata-rata hitung 7,19, loncat jauh tanpa awalan rata-rata hitung 183,79 dan lari zig-zag rata-rata hitung 12,1 dari 27 siswa putra, sedangkan kelompok putri lari 50 meter dengan rata-rata hitung 9,63, loncat jauh tanpa awalan rata-rata hitung 153,39 dan lari zig-zag rata-rata hitung 14,10 dari 27 siswa putri, jadi hasil kemampuan gerak dasar lokomotor siswa kelas VII SMP Darussalam Kecamatan Kademangan Kabupaten Blitar termasuk dalam kategori standar (Arif, 2017). Untuk mengetahui perkembangan gerak dasar siswa maka perlu dilakukan kajian berupa penelitian terkait gerak dasar lokomotor, nonlokomotor dan manipulatif dalam bentuk tes melalui penelitian terhadap keterampilan gerak dasar. 
Berdasarkan penelitian terdahulu serta hasil observasi yang telah dilakukan, maka perlu diadakan tes atau pengukuran tentang keterampilan gerak dasar (lokomotor, non lokomotor, dan manipulatif) agar hasil tes pengukuran tersebut dapat digunakan oleh guru PJOK untuk menyusun rancangan pembelajaran sehingga tujuan pembelajaran dapat tercapai. Oleh karena itu peneliti melakukan penelitian dengan judul "Survei Keterampilan Gerak Dasar Pada Siswa Kelas VII Di SMP Laboratorium UM Kota Malang”

Penelitian ini bertujuan untuk memperoleh dan mengkaji informasi tentang kemampuan keterampilan gerak dasar pada kelompok siswa putra dan kelompok putri kelas VII di SMP Laboratorium UM Kota Malang.

\section{Metode}

Penelitian ini menggunakan rancangan penelitian bentuk deskriptif kuantitatif dengan metode survei. Populasi yang digunakan pada penelitian ini berjumlah 251 siswa kelas VII (AI) di SMP Laboratorium UM Kota Malang, sedangkan sampel dalam penelitian berjumlah 120 siswa dari kelas D, E, F dan H, teknik sampel yang digunakan yaitu Purposive Proportional Random Sampling dengan porsi 50\%. Teknik Proportional Sampling yaitu menggunakan porsi 50\% dari 4 kelas berjumlah 60 siswa sedangkan Purposive Sampling yaitu ditujukan kepada siswa kelas VII D dan VII H berjumlah 60 siswa (24 siswa putra dan 36 siswa putri). Instrumen yang digunakan pada penelitian ini yaitu instrumen tes bentuk keterampilan gerak dasar dan non tes bentuk observasi. Pengumpulan data dalam penelitian menggunakan teknik pengukuran bentuk tes fisik yaitu keterampilan gerak dasar berupa beberapa macam tes gerak dasar, meliputi tes lokomotor (lari zig-zag, shuttle run, side jump, side hop jump gawang dan loncat jauh tanpa awalan,) tes non lokomotor (sit up, back up dan kayang) dan tes manipulatif (melempar bola basket tanpa awalan dan dribble bola basket zig-zag). Sedangkan teknik pengukuran bentuk non tes berupa observasi (pengamatan) digunakan untuk mengamati gerakan siswa saat melakukan tes keterampilan gerak dasar lokomotor, non lokomotor dan manipulatif. Analisis data yang digunakan dalam penelitian ini adalah teknik statistika deskriptif kuantitatif bentuk tendensi central meliputi mean, median dan modus \& variabilita meliputi variansi sampel, standar deviasi sampel dan koefisien variansi.

\section{Hasil dan Pembahasan}

\subsection{Hasil}

Data yang telah diperoleh kemudian dianalisis menggunakan teknik statistika deskriptif kuantitatif. Pada Tabel 1 disajikan distribusi frekuensi relatif dari hasil tes keterampilan gerak dasar (lokomotor, non lokomotor, dan manipulatif). Berdasarkan sajian hasil analisi data pada Tabel 1, bahwa data yang telah diperoleh dari hasil tes keterampilan gerak dasar (lokomotor, nonlokomotor dan manipulatif) pada siswa putra kelas VII di SMP Laboratorium UM Kota Malang yang menggunakan sampel berjumlah 24 siswa dianalisis menggunakan statistika deskriptif bentuk penyebaran data, hasil tes pada unsur gerak dasar lokomotor yang meliputi (1) tes lari shuttle run hasil skor mean 8,81 detik, skor standart devisiasi sampel 1,27 detik, skor variansi sampel 1,63 detik, skor koefisien variansi 14,49\%, (2) tes lari zig-zag hasil skor mean 6,13 detik, skor standart devisiasi sampel 0,79 detik, skor variansi sampel 0,62 detik, skor koefisien variansi 12,93\%, (3) tes side hop jump gawang hasil skor mean 20,75 kali, skor standart devisiasi sampel 4,39 kali, skor variansi sampel 19,32 kali, skor koefisien variansi 21,19\%, (4) tes side jump hasil skor mean 20,70 kali, skor standart devisiasi sampel 4,39 kali, 
skor variansi sampel 19,34 kali, skor koefisien variansi 21,24\%, dan (5) tes loncat jauh tanpa awalan hasil skor mean 1,59 meter, skor standart devisiasi sampel 0,47 meter, skor variansi sampel 0,22 meter, skor koefisien variansi 29,66\%, hasil tes pada unsur keterampilan gerak dasar nonlokmotor yang meliputi (1) tes sit up hasil skor mean 12,33 kali, skor standart devisiasi sampel 2,27 kali, skor variansi sampel 5,18 kali, skor koefisien variansi 18,47\%, (2) tes kayang hasil skor mean $56,12 \mathrm{~cm}$, skor standart devisiasi sampel 13,29 $\mathrm{cm}$, skor variansi sampel 176,72 cm, skor koefisien variansi 23,69\%, dan (3) hasil skor mean 21,83 kali, skor standart devisiasi sampel 3,63 kali, skor variansi sampel 13,18 kali, skor koefisien variansi $16,63 \%$, sedangkan hasil tes pada unsur gerak dasar manipulatif yang meliputi (1) tes melempar bola basket tanpa awalan hasil skor mean 4,94 meter, skor standart devisiasi sampel 1,13 meter, skor variansi sampel 1,28 meter, skor koefisien variansi 22,90\%, dan (2) tes dribble bola basket zig-zag hasil skor mean 12,37 detik, skor standart devisiasi sampel 3,11 detik, skor variansi sampel 9,69 detik, skor kefisien variansi $25,15 \%$.

Tabel 1. Hasil Analisis Keseluruhan Butir Tes Siswa Putra Kelas VII SMP Laboratorium UM Kota Malang

\begin{tabular}{llllll}
\hline \multirow{2}{*}{$\begin{array}{c}\text { Macam Gerak } \\
\text { Dasar }\end{array}$} & \multicolumn{1}{c}{ Jenis Tes } & \multicolumn{3}{c}{ Jenis Ukuran Variabilita } \\
\cline { 2 - 5 } Lokolomor & Lari shuttle run & Mean & \multicolumn{1}{c}{ SD.S } & Variansi.S & KV (\%) \\
& Lari zig-zag & $6,13 \mathrm{detik}$ & $1,27 \mathrm{detik}$ & $1,63 \mathrm{detik}$ & 14,49 \\
& Side hop jump gawang & $20,75 \mathrm{kali}$ & $4,39 \mathrm{kali}$ & $0,62 \mathrm{detik}$ & 12,93 \\
& Side Jump & $20,70 \mathrm{kali}$ & $4,39 \mathrm{kali}$ & $19,34 \mathrm{kali}$ & 21,19 \\
& Loncat jauh tanpa awalan & 21,24 \\
\multirow{5}{*}{ Nonlokomotor } & $1,59 \mathrm{~meter}$ & $0,47 \mathrm{~meter}$ & $0,22 \mathrm{~meter}$ & 29,66 \\
& Sit Up & $12,33 \mathrm{kali}$ & $2,27 \mathrm{kali}$ & $5,18 \mathrm{kali}$ & 18,47 \\
& Kayang & $56,12 \mathrm{~cm}$ & $13,29 \mathrm{~cm}$ & $176,72 \mathrm{~cm}$ & 23,69 \\
\multirow{3}{*}{ Manipulaif } & Back Up & $21,83 \mathrm{kali}$ & $3,63 \mathrm{kali}$ & $13,18 \mathrm{kali}$ & 16,63 \\
& Melempar bola basket & 4,94 meter & 1,13 meter & 1,28 meter & 22,90 \\
& tanpa awalan & & & \\
& Dribble bola basket zig-zag & 12,37 detik & 3,11 detik & 9,69 detik & 25,15 \\
\hline
\end{tabular}

Tabel 2. Hasil Analisis Keseluruhan Butir Tes Siswa Putri Kelas VII SMP Laboratorium UM Kota Malang

\begin{tabular}{|c|c|c|c|c|c|}
\hline \multirow{2}{*}{$\begin{array}{l}\text { Macam Gerak } \\
\text { Dasar }\end{array}$} & \multirow{2}{*}{ Jenis Tes } & \multicolumn{4}{|c|}{ Jenis Ukuran Variabilita } \\
\hline & & Mean & SD.S & Variansi.S & KV (\%) \\
\hline \multirow{5}{*}{ Lokolomor } & Lari shuttle run & 9,24 detik & 0,96 detik & 0,93 detik & 10,47 \\
\hline & Lari zig-zag & 6,33 detik & 0,61 detik & 0,38 detik & 9,77 \\
\hline & Side hop jump gawang & 19,08 kali & 3,12 kali & 9,79 kali & 16,40 \\
\hline & Side Jump & 16,08 kali & 3,00 kali & 9,05 kali & 18,70 \\
\hline & Loncat jauh & 1,50 meter & 0,51 meter & 0,26 meter & 34,17 \\
\hline \multirow{3}{*}{ Nonlokomotor } & Sit Up & 11,83 kali & 1,63 kali & 2,65 kali & 13,78 \\
\hline & Kayang & $52,02 \mathrm{~cm}$ & $12,47 \mathrm{~cm}$ & $155,68 \mathrm{~cm}$ & 23,98 \\
\hline & Back Up & 19,02 kali & 3,30 kali & 10,94 kali & 17,38 \\
\hline \multirow[t]{2}{*}{ Manipulaif } & $\begin{array}{l}\text { Melempar bola basket tanpa } \\
\text { awalan }\end{array}$ & 3,74 meter & 0,81 meter & 0,66 meter & 21,69 \\
\hline & Dribble bola basket zig-zag & 12,86 detik & 2,33 detik & 5,46 detik & 18,16 \\
\hline
\end{tabular}

Berdasarkan sajian hasil analisis data pada Tabel 2, bahwa data yang telah diperoleh dari hasil tes keterampilan gerak dasar (lokomotor, non lokomotor dan manipulatif) pada siswa putri kelas VII di SMP Laboratorium UM Kota Malang yang menggunakan sampel berjumlah 36 
siswa dianalisis menggunakan statistika deskriptif bentuk penyebaran data, hasil tes pada unsur gerak dasar lokomotor yang meliputi (1) tes lari shuttle run hasil skor mean 9,24 detik, skor standar deviasi sampel 0,96 detik, skor variansi sampel 0,93 detik, skor koefisien variansi 10,47\%, (2) tes lari zig-zag hasil skor mean 6,33 detik, skor standar deviasi sampel 0,61 detik, skor variansi sampel 0,38 detik, skor koefisien variansi 9,77\%, (3) tes side hop jump gawang hasil skor mean 19,08 kali, skor standar deviasi sampel 3,12 kali, skor variansi sampel 9,79 kali, skor koefisien variansi 16,40\%, (4) tes side jump hasil skor mean 16,08 kali, skor standar deviasi sampel 3,00 kali, skor variansi sampel 9,05 kali, skor koefisien variansi 18,70\%, dan (5) tes loncat jauh tanpa awalan hasil skor mean 1,50 meter, skor standar deviasi sampel 0,51 meter, skor variansi sampel 0,26 meter, skor koefisien variansi 34,17\%, hasil tes pada unsur keterampilan gerak dasar non lokomotor yang meliputi (1) tes sit up hasil skor mean 11,83 kali, skor standar deviasi sampel 1,63 kali, skor variansi sampel 2,65 kali, skor koefisien variansi 13,78\%, (2) tes kayang hasil skor mean 52,02 cm, skor standar deviasi sampel $12,47 \mathrm{~cm}$, skor variansi sampel 155,68 cm, skor koefisien variansi 23,98\%, dan (3) tes backup hasil skor mean 19,02 kali, skor standar deviasi sampel 3,30 kali, skor variansi sampel 10,94 kali, skor koefisien variansi $17,38 \%$, sedangkan hasil tes pada unsur gerak dasar manipulatif yang meliputi (1) tes melempar bola basket tanpa awalan hasil skor mean 3,74 meter, skor standar deviasi sampel 0,81 meter, skor variansi sampel 0,66 meter, skor koefisien variansi 21,69\%, dan (2) tes dribble bola basket zig-zag hasil skor mean 12,86 detik, skor standar deviasi sampel 2,33 detik, skor variansi sampel 5,46 detik, skor koefisien variansi 18,16\%.

Tabel 3. Distribusi Frekuensi Relatif Keseluruhan dan Kriteria Tes Keterampilan Gerak Dasar Siswa Putra Kelas VII SMP Laboratorium UM Kota Malang

\begin{tabular}{llccc}
\hline Macam Gerak & \multicolumn{1}{c}{ Jenis Tes } & \multicolumn{3}{c}{ Hasil Analisi Data } \\
\cline { 3 - 5 } Dasar & & Fo & FR (\%) & Kriteria \\
\hline Lokolomor & Lari shuttle run & 9 & 38 & Cukup Baik \\
& Lari zig-zag & 9 & 38 & Cukup Baik \\
& Side hop jump gawang & 12 & 50 & Cukup Baik \\
& Side Jump & 11 & 46 & Cukup Baik \\
& Loncat jauh tanpa awalan & 11 & 46 & Cukup Baik \\
\multirow{5}{*}{ Nonlokomotor } & Sit Up & 12 & 50 & Cukup Baik \\
& Kayang & 10 & 42 & Kurang Baik \\
& Back Up & 9 & 38 & Kurang Baik \\
Manipulaif & Melempar bola basket tanpa awalan & 9 & 38 & Kurang Baik \\
& Dribble bola basket zig-zag & 10 & 42 & Cukup Baik \\
\hline
\end{tabular}

Keterangan:

Fo : Frekuensi Observasi

FR : Frekuensi Relatif

Berdasarkan distribusi Frekuensi Relatif seluruh butir tes siswa putra kelas VII SMP Laboratorium UM Kota Malang pada Tabel 3 mendapatkan hasil tes lari shuttle run dominan pada kriteria cukup baik dengan persentase 38\%, hasil tes lari zig-zag dominan pada kriteria cukup baik dengan persentase $38 \%$, hasil tes side hop jump gawang dominan pada kriteria cukup baik dengan persentase 50\%, hasil tes side jump dominan pada kriteria cukup baik dengan persentase $46 \%$, hasil tes loncat jauh tanpa awalan dominan pada kriteria cukup baik dengan persentase $46 \%$, hasil tes sit up dominan pada kriteria cukup baik dengan persentase $50 \%$, hasil tes kayang dominan pada kriteria kurang baik dengan persentase $42 \%$, hasil tes back up dominan pada kriteria kurang baik dengan persentase $38 \%$, hasil tes melempar bola basket tanpa awalan dominan pada kriteria kurang baik dengan persentase $38 \%$, dan hasil tes 
dribble bola basket zig-zag dominan pada kriteria cukup baik dengan persentase $42 \%$. Tabel 3 menunjukan hasil frekuensi terbanyak siswa putra kelas VII SMP Laboratorium UM Kota Malang yang melakukan tes lari shuttle run, tes lari zig-zag, tes side hop jump gawang, tes side jump, tes loncat jauh tanpa awalan, tes sit up, tes kayang, tes back up, tes melempar bola basket tanpa awalan, dan tes dribble bola basket zig-zag.

\section{Tabel 4. Distribusi Frekuensi Relatif Keseluruhan dan Kriteria Tes Keterampilan Gerak Dasar Siswa Putri Kelas VII SMP Laboratorium UM Kota Malang}

\begin{tabular}{llccc}
\hline Macam Gerak & \multicolumn{1}{c}{ Jenis Tes } & \multicolumn{3}{c}{ Hasil Analisi Data } \\
\cline { 3 - 5 } Dasar & \multicolumn{1}{c}{ Fo } & FR (\%) & Kriteria \\
\hline Lokolomor & Lari shuttle run & 16 & 44 & Cukup Baik \\
& Lari zig-zag & 14 & 39 & Kurang Baik \\
& Side hop jump gawang & 11 & 31 & Cukup Baik \\
& Side Jump & 14 & 39 & Cukup Baik \\
& Loncat jauh tanpa awalan & 15 & 42 & Kurang Baik \\
\multirow{5}{*}{ Nonlokomotor } & Sit Up & 12 & 33 & Cukup Baik \\
& Kayang & 11 & 31 & Cukup Baik \\
& Back Up & 17 & 47 & Cukup Baik \\
Manipulaif & Melempar bola basket tanpa awalan & 16 & 44 & Cukup Baik \\
& Dribble bola basket zig-zag & 18 & 50 & Cukup Baik \\
\hline
\end{tabular}

Berdasarkan distribusi Frekuensi Relatif seluruh butir tes siswa putra kelas VII SMP Laboratorium UM Kota Malang pada Tabel 4 mendapatkan hasil tes lari shuttle run dominan pada kriteria cukup baik dengan persentase $44 \%$, hasil tes lari zig-zag dominan pada kriteria kurang baik dengan persentase $39 \%$, hasil tes side hop jump gawang dominan pada kriteria cukup baik dengan persentase 31\%, hasil tes side jump dominan pada kriteria cukup baik dengan persentase $39 \%$, hasil tes loncat jauh tanpa awalan dominan pada kriteria kurang baik dengan persentase $42 \%$, hasil tes sit up dominan pada kriteria cukup baik dengan persentase $33 \%$, hasil tes kayang dominan pada kriteria cukup baik dengan persentase $31 \%$, hasil tes back up dominan pada kriteria cukup baik dengan persentase $47 \%$, hasil tes melempar bola basket tanpa awalan dominan pada kriteria cukup baik dengan persentase $44 \%$, dan hasil tes dribble bola basket zig-zag dominan pada kriteria cukup baik dengan persentase 50\%. Tabel 4 menunjukan hasil frekuensi terbanyak siswa putra kelas VII SMP Laboratorium UM Kota Malang yang melakukan tes lari shuttle run, tes lari zig-zag, tes side hop jump gawang, tes side jump, tes loncat jauh tanpa awalan, tes sit up, tes kayang, tes back up, tes melempar bola basket tanpa awalan, dan tes dribble bola basket zig-zag.

\subsection{Pembahasan}

Hasil tes keterampilan gerak dasar lokomotor unsur lari bentuk tes lari shuttle run dan lari zig-zag, hasil tes unsur lompat dengan menggunakan tes side hop jump gawang, dan hasil tes unsur loncat menggunakan tes side jump \& loncat jauh tanpa awalan pada siswa siswa kelompok putra dan putri penelitian menunjukkan dominan cenderung pada kategori cukup baik (belum baik). Hal yang dapat menyebabkan berada pada kondisi yang belum baik yaitu karena kondisi yang terjadi ketika pembelajaran pendidikan jasmani, olahraga dan kesehatan (PJOK) di SMP Laboratorium UM Kota Malang, ketika proses pembelajaran dalam dua lapangan (lapangan voli dan lapangan basket) yang digunakan oleh tiga kelas dengan berbeda tingkatan dalam waktu bersamaan seperti lapangan basket yang harus digunakan oleh dua kelas yang 
berbeda tingkatan, sehingga aktivitas gerak yang dilakukan ketika melakukan pemanasan atau melakukan materi pembelajaran yang melibatkan aktivitas gerak lari, lompat dan loncat tidak dapat dilakukan secara maksimal oleh siswa. Jika siswa memiliki keterampilan gerak dasar yang berada pada kriteria baik, maka aktivitas gerak dalam pembelajaran sangat penting untuk dimaksimalkan. Dengan kondisi lapangan yang terbatas, maka aktivitas gerak yang dilakukan oleh siswa juga terbatas sehingga berdampak pada keterampilan gerak dasar khususnya pada gerak dasar lokomotor yang meliputi unsur lari, unsur lompat dan unsur loncat. Pada cabang olahraga atletik unsur lari pada nomor lari cepat (sprint), unsur lompat pada nomor lompat jauh, dan unsur loncat pada nomor loncat tinggi dan juga sebagai media awal untuk melakukan aktivitas (pemanasan).

Terkait dengan keterampilan gerak dasar aspek lokomotor pada unsur lari, lompat dan loncat dalam pembelajaran keterampilan terdapat penelitian untuk dapat meningkatkan keterampilan gerak dasar lokomotor pada unsur lari bahwa terdapat hubungan yang signifikan antara kecepatan lari dengan menggiring bola pada permainan sepak bola oleh siswa putra kelas VIII SMPN 1 Sape Kabupaten Bima, berarti dengan bertambahnya kecepatan lari maka akan diikuti pula dengan kecepatan menggiring bola (Anhar \& Irwan, 2017). Untuk dapat meningkatkan keterampilan gerak dasar lokomotor khususnya pada unsur lari bisa menggunakan metode picture and picture yang dirancang sesuai dengan kebutuhan anak agar memberikan pembelajaran yang menyenangkan yang dapat meningkatkan gerak lokomotor lari 40 meter (Riyanto, 2017). Pada unsur lompat dan loncat terdapat penelitian yang menyatakan suatu hubungan yang signifikan antara daya ledak terhadap kemampuan lompat jauh siswa dengan nilai $r=0,87$ (Haeril, H., \& Arum, 2019). Untuk meningkatkan kemampuan gerak dasar unsur lompat dengan melalui modifikasi permainan tradisional engklek, hasilnya dibuktikan dengan rata-rata siklus I sebesar 68,50 sedangkan pada siklus II sebesar 76,97 berarti terjadi peningkatan dari siklus I ke siklus II (Ardhika 2015). Terdapat pengaruh latihan loncat gawang setinggi $25 \mathrm{~cm}$ dengan jarak 0,5 m terhadap peningkatan daya ledak otot tungkai pada peserta ekstrakurikuler bola voli putra di SMP N 2 Sukawati (Puspayuda, Darmada, \& Dewi, 2016). Sedangkan untuk dapat meningkatkan keterampilan gerak dasar unsur loncat dapat menggunakan permainan modifikasi balon, hal ini dapat dilihat dari hasil rata-rata pada siklus I sebesar 60,00\% meningkat menjadi $80,00 \%$ di siklus II (Nurfa \& Hasibuan, 2017).

Adapun penelitian terdahulu yang dapat meningkatkan keterampilan gerak dasar lokomotor yang berjudul "Peningkatan Keterampilan Gerak Dasar Lokomotor Menggunakan Metode Bermain Dalam Pembelajaran Pendidikan Jasmani Siswa Kelas III C SDN Krian 3 Kabupaten Sidoarjo" kesimpulan hasil penelitian menunjukkan bahwa adanya peningkatan hasil belajar dari siklus I ke siklus II. Pada siklus I peningkatan keterampilan gerak dasar lokomotor menggunakan metode bermain yaitu sebesar $90 \%$ dan siklus 2 adalah sebesar $97 \%$ (Agustini, Tomi, \& Sudjana, 2016).

Hasil tes gerak dasar nonlokomotor bentuk tes sit up,kayang, dan back up pada siswa kelompok putra dan putri penelitian menunjukkan dominan cenderung pada kategori cukup baik (belum baik). Kemampuan keterampilan gerak dasar nonlokomotor seharusnya berada pada kondisi yang baik, tetapi pada kenyataanya kemampuan keterampilan gerak dasar nonlokomotor berada pada kondisi yang cukup baik (belum baik). Hal ini disebabkan karena kondisi yang terjadi ketika pembelajaran pendidikan jasmani, olahraga dan kesehatan (PJOK) di SMP Laboratorium UM Kota Malang, ketika proses pembelajaran siswa banyak yang tidak 
memperhatikan penjelasan dari guru (bergurau), sehingga siswa belum benar-benar menguasai materi pembelajaran yang sudah diajarkan dan siswa belum pernah melakukan materi aktivitas gerak gerak seperti senam lantai pada jenjang sebelumnya, sehingga siswa mengalami kesulitan ketika melakukannya. Jika siswa mempunyai keterampilan gerak dasar yang berada pada kriteria baik, maka aktivitas gerak dalam pembelajaran sangat penting untuk dimaksimalkan. Jika terdapat kondisi lapangan yang terbatas, maka aktivitas gerak yang dilakukan oleh siswa juga terbatas sehingga berdampak pada keterampilan gerak dasar. Maka dari itu penting untuk meningkatkan suatu keterampilan gerak dasar khususnya pada gerak dasar nonlokomotor dalam pembelajaran pendidikan jasmani, olahraga dan kesehatan maupun diluar pembelajaran agar dapat menunjang dalam materi pembelajaran pendidikan jasmani seperti cabang olahraga senam lantai yang membutuhkan kelentukan menekuk badan ketika melakukan roll depan, roll belakang ataupun kayang. Sehubung dengan hasil tes keterampilan gerak dasar nonlokomotor yang berada pada kriteria cukup baik sampai dengan tidak baik. Adapun hasil penelitian untuk dapat meningkatkan keterampilan gerak dasar non lokomotor yang terdapat pengaruh latihan back up terhadap kemampuan heading dalam permainan sepak bola pada siswa MTs Alkhairaat Pinotu Kabupaten Parigi Moutong (Reval 2013:1). Sedangkan hasil penelitian yang menunjukkan bahwa terdapat hubungan yang signifikan antara keterampilan gerak dasar lokomotor terhadap kayang (Jamilah \& Nugraheni, 2017).

Hasil tes gerak dasar manipulatif bentuk tes melempar bola basket tanpa awalan dan tes dribble bola basket zig-zag pada siswa siswa kelompok putra dan putri penelitian menunjukkan dominan cenderung pada kategori cukup baik (belum baik). Kemampuan keterampilan gerak dasar manipulatif seharusnya berada pada kondisi yang baik, tetapi pada kenyataanya kemampuan keterampilan gerak dasar manipulatif pada berada pada kondisi yang belum baik. Hal yang dapat menyebabkan berada pada kondisi yang belum baik yaitu karena kondisi yang terjadi ketika pembelajaran pendidikan jasmani, olahraga dan kesehatan (PJOK) di SMP Laboratorium UM Kota Malang, ketika proses pembelajaran dalam dua lapangan (lapangan voli dan lapangan basket) yang digunakan oleh tiga kelas dengan berbeda tingkatan dalam waktu bersamaan seperti lapangan basket yang harus digunakan oleh dua kelas yang berbeda tingkatan, sehingga aktivitas gerak yang dilakukan sehingga aktivitas gerak yang dilakukan tidak maksimal, siswa belum benar-benar menguasai materi pembelajaran yang sudah diajarkan oleh guru pada semester gasal \& genap seperti lupa dengan cara-cara melakukannya (teknik-tekniknya) karena ketika proses pembelajaran siswa tidak memperhatikan materi pembelajaran yang dijelaskan oleh guru dan juga siswa baru mendapatkan materi yang lebih kompleks ketika jenjang SMP seperti materi bola basket (melempar dan menggiring). Jika siswa mempunyai keterampilan gerak dasar yang berada pada kriteria baik, maka aktivitas gerak dalam pembelajaran sangat penting untuk dimaksimalkan. Jika kondisi lapangan yang terbatas, maka aktivitas gerak yang dilakukan oleh siswa juga terbatas sehingga berdampak pada keterampilan gerak dasar. Maka dari itu penting untuk meningkatkan suatu keterampilan gerak dasar khususnya pada gerak dasar manipulatif dalam pembelajaran pendidikan jasmani, olahraga dan kesehatan maupun diluar pembelajaran agar dapat menunjang dalam materi pembelajaran pendidikan jasmani seperti cabang olahraga bola besar yang membutuhkan anggota tubuh atau alat yang meliputi olahraga bola basket, bola voli, sepak bola dan lain-lain. Sehubung dengan hasil tes pada keterampilan gerak dasar manipulatif yang berada pada kriteria cukup baik sampai dengan tidak baik. Terkait penelitian untuk dapat meningkatkan keterampilan gerak dasar manipulatif 
bahwa untuk dapat meningkat ketuntasan dengan menggunakan variasi keterampilan dasar lempar tangkap pada siswa dengan persentase pada siklus I sebesar $61,11 \%$ dan siklus II sebesar 94,44\% (Dongoran 2013:95). Untuk dapat meningkatkan keterampilan gerak dasar manipulatif dapat menggunakan pembelajaran dengan metode drill dinamis dan statis dapat meningkatkan hasil belajar lempar jauh bola softball (Pradana, 2019). Untuk meningkatkan dribble bolabasket pada keterampilan gerak dasar manipulatif menggunakan metode part and whole (Baqiyudin \& Sudarsono, 2013). Sedangkan untuk meningkatkan keterampilan gerak dasar manipulatif dengan menggunakan keterampilan gerak dasar lempar lembing anak siswa kelas 5 SD (Wijayanti \& Suntoda, 2017).

Adapun hasil penelitian terdahulu untuk dapat meningkatkan keterampilan gerak dasar yang berjudul "Kemampuan Gerak Dasar Pada Siswa-Siswi Kelas V Sekolah Dasar Negeri 7 Sungai Kakap Kabupaten Kubu Raya" menunjukkan bahwa kemampuan gerak dasar dalam kategori cukup dimana (1) tes lempar tangkap bola jarak 1 meter ke tembok rata-rata sebesar $53,33 \%$ (2) kemampuan tes lari cepat 30 meter dalam kelompok baik dengan rata-rata sebesar 43,33\% (3) kemampuan tes standing long jump tergolong baik dengan rata-rata sebesar $53,33 \%$ (4) kemampuan keseimbangan (tes stork stand) termasuk kategori baik dengan ratarata sebesar 43,33\% (5) kemampuan tes kelincahan tergolong dalam kategori baik dengan rata-rata sebesar $40 \%$. Berarti kemampuan gerak dasar lokomotor yang berupa tes lari cepat 30 meter, tes standing long jump, tes kelincahan termasuk dalam kategori baik, kemampuan gerak dasar non lokomotor yaitu tes keseimbangan (tes stork stand) termasuk kategori baik, dan kemampuan gerak dasar manipulatif yaitu pada tes tangkap bola jarak 1 meter ke tembok termasuk kategori cukup (Agus, Victor, \& Wiwik 2014). Penelitian yang berjudul "Peningkatan Aktivitas Gerak Lokomotor, Non Lokomotor dan Manipulatif Menggunakan Model Permainan Pada Siswa Sekolah Dasar" kesimpulan dari hasil penelitian yaitu melalui penerapan metode bermain kera panjat dalam penelitian tindakan kelas ini diketahui bahwa terjadi peningkatan keaktifan siswa pada gerak lokomotor sebesar 70\%, gerak non lokomotor 54\% dan gerak manipulatif 83,3\% (Hidayat 2017:21). Penelitian dengan judul "Hubungan Kemampuan Motor Ability dengan Keterampilan Bermain Sepak Bola Pada Klub Himadirga Unsyiah" dengan hasil bahwa terdapat hubungan yang signifikan antara kemampuan motorik ability terhadap keterampilan bermain sepak bola dengan hasil T hitung 9,39 > T Tabel 1,75 (Nusufi, 2016). Sedangkan penelitian yang berjudul "Permainan Invasi Dan Permainan Netting Untuk Meningkatkan Keterampilan Gerak Dasar Fundamental Siswa Sd Negeri Se Kecamatan Mojoroto Kota Kediri" yang menunjukkan hasil bahwa permainan invasi dan permainan netting memberikan pengaruh terhadap keterampilan gerak dasar pada siswa (Burstiando \& Kholis, 2017).

\section{Simpulan}

Berdasarkan hasil analisis data dalam penelitian keterampilan gerak dasar pada siswa kelas VII di SMP Laboratorium UM Kota Malang, maka penelitian ini dapat disimpulkan sebagai berikut. (1) Kemampuan keterampilan gerak dasar aspek lokomotor kelompok putra dan putri kelas VII SMP Laboratorium UM Kota Malang secara keseluruhan tergolong pada kriteria cukup baik (belum baik). (2) Kemampuan keterampilan gerak dasar aspek nonlokomotor kelompok putra dan putri kelas VII SMP Laboratorium UM Kota Malang secara keseluruhan tergolong pada kriteria cukup baik (belum baik). (3) Kemampuan keterampilan gerak dasar aspek manipulatif kelompok putra dan putri kelas VII SMP Laboratorium UM Kota Malang secara keseluruhan tergolong pada kriteria cukup baik (belum baik). (4) Jadi kesimpulan dari hasil penelitian keterampilan gerak dasar yang meliputi gerak dasar lokomotor, nonlokomotor dan 
manipulatif pada siswa kelas VII di SMP Laboratorium UM Kota Malang termasuk dalam kategori cukup baik (belum baik). Adapun hasil analisis data penelitian yang sudah dipaparkan, saran dari peneiti bagai berbagai pihak seperi berikut ini. (1) Bagi siswa SMP Laboratorium UM Kota Malang, diharapkan untuk lebih aktif dalam berlatih mengenai keterampilan gerak dasar lokomotor, nonlokomotor dan manipulatif setelah mengetahui kondisi kemampuan gerak dasarnya. (2) Bagi guru PJOK, diharapkan penelitian ini digunakan sebagai dasar untuk menyusun \& mengembangkan Rencana Pelaksanaan Pembelajaran dan menjadi acuan untuk dapat mengetahui tingkat keterampilan gerak dasar pada siswa dengan cara mengadakan tes awal tentang keterampilan gerak dasar.

\section{Daftar Rujukan}

Anhar \& Irwan. (2017). Hubungan Kecepatan Lari dengan Keterampilan Menggiring Bola Bola Dalam Permainan Sepak Bola Pada Siswa Putra Kelas VIII SMP Negeri 1 Sape Tahun Pelajaran 2013/2014. Jurnal Pendidikan Olahraga, 7(1), 8-15.

Ardhika, D. F. (2015). Upaya Meningkatkan Hasil Belajar Gerak Dasar Lompat Melalui Modifikasi Permainan Tradisional Engklek Pada Siswa Kelas II SD Negeri 2 Jeruk Kabupaten Blora Tahun 2013/2014. Journal of Physical Education, Sport, Health, and Recreations, 4(1), 1503-1508. https://doi.org/10.15294/active.v4i1.4557

Arif, Z. (2017). Survei Kemampuan Gerak Lokomotor pada Siswa Kelas VII SMP Darussalam Kecamatan Kademangan Kabupaten Blitar. Skripsi tidak diterbitkan. Universitas Negeri Malang.

Bakhtiar, S. (2015). Merancang Pembelajaran Gerak Dasar Anak. In Merancang Pembelajaran Gerak Dasar Anak. Retrieved from http://repositiry.unp.ac.id/65/1/SYAHRIAL BAKHTIAR BUKU 1.pdf.

Baqiyudin, G., \& Sudarsono. (2013). Perbandingan Metode Pembelajaran Whole Practice Dan Part Practice Terhadap Hasil Belajar Dribbling Bolabasket (Studi Pada Siswa Kelas Vii Smpn 1 Jogoroto Jombang). Jurnal Pendidikan Olahraga Dan Kesehatan, 01(1), 252-254.

Buchur, A. (2018). Survei Tingkat Keterampilan Gerak (Motor Ability) Siswa Putra Kelas Viii Tingkat Sltp SeKecamatan Pucanglaban Kabupaten Tulungagung Tahun Ajaran 2017/2018. Jurnal Simki-Techsain, 2(5), 1-12. Retrieved from http://simki.unpkediri.ac.id/detail/13.1.01.09.0116

Budiono, A., Simanjuntak, V., \& Yunitaningrum, W. (2013). Survey Kemampuan Gerak Dasar pada Siswa-siswi Kelas V Sekolah Dasar Negeri 7 Sungai Kakap Kabupaten Kubu Raya. Jurnal Pendidikan dan Pembelajaran Khatulistiwa, 3(6).

Burstiando, R., \& Kholis, M. N. (2017). Permainan Invasi Dan Permainan Netting Untuk Meningkatkan Keterampilan Gerak Dasar Fundamental Siswa Sd Negeri Se Kecamatan Mojoroto Kota Kediri. Jurnal Pembelajaran Olahraga, 3(2), 167-177. https://doi.org/10.1097/00001888-199401000-00014

Dongoran, B. (2013). Upaya Meningkatkan Hasil Belajar Passing dalam Permainan Bola Basket Melalui Keterampiln Dasar Lempar Tangkap Bola. Jurnal Handayani PGSD FIP Unimed, 1(1), 86-96. https://doi.org/10.1017/CB09781107415324.004

Fadilah, M., \& Wibowo, R. (2018). Kontribusi Keterampilan Gerak Fundamental Terhadap Keterampilan Bermain Small-Sided Handball Games. Jurnal Pendidikan Jasmani Dan Olahraga, 3(1), 60-68. https://doi.org/10.17509/jpjo.v3i1.7667

Hanief, Y. N. (2015). embentuk Gerak Dasar pada Siswa Sekolah Dasar Melalui Permainan Tradisional. Jurnal Sportif, 1(1), 60. https://doi.org/10.29407/js_unpgri.v1i1.575

Jamilah, G., \& Nugraheni, W. (2017). Hubungan antara Fleksibilitas Otot Perut dengan Keterampilan Gerak Dasar Kayang dalam Senam Artistik. Hubungan Antara Fleksibilitas Otot Perut Dengan Keterampilan Gerak Dasar Kayang Dalam Senam Artistik, 7(2), 56-59. https://doi.org/10.15294/miki.v7i2.12148

Nurfa, I. \& Hasibuan, R. (2017). Meningkatkan Kemampuan Melompat Melalui Permainan Modifikasi Balon Pada Anak Kelompok A TK Pancamurni I Kertosono Kabupaten Nganjuk. Jurnal PAUD Teratai, 6(3), 16.

Nusufi, M. (2016). Hubungan Keterampilan Motor Ability dengan Keterampilan Bermain Sepak Bola Pada Klub Himadirga Unsyiah. Jurnal Pedagogik Keolahragaan, 02(01), 1-10. Retrieved from https://jurnal.unimed.ac.id/2012/index.php/jpor/article/view/5404 
Pradana, A. (2019). Pengaruh Pembelajaran Metode Drill Terhadap Peningkatan Hasil Belajar Lempar Bola Softball Kelas 7 Smp Negeri 1 Kota Malang. Jurnal Gelanggang Pendidikan Jasmani Indonesia, 3(2), 121129. Retrieved from http://dx.doi.org/10.17977/um040v3i2p121-129

Reval, R. (2013). Pengaruh Latihan Back Up Terhadap Kemampuan Heading dalam Permainan Sepak Bola pada Siswa MTs Alkhairaat Pinotu Kabupaten Parigi Moutong. Tadulako Jurnal Sport Sciences And Physical Education, 1(3), 1-15.

Riyanto, S. (2017). Upaya Meningkatkan Gerak Lokomotor Lari 40 Meter Melalui Metode Picture and Picture kelas IIA SDS Kristen Kanaan Kubu Raya. Jurnal Pendidikan Dan Pembelajaran Khatulistiwa, 6(3). https://doi.org/10.1017/CB09781107415324.004

Sepriadi, S. (2017). Kontribusi status gizi dan kemampuan motorik terhadap kesegaran jasmani siswa sekolah dasar. Jurnal Keolahragaan, 5(2), 194-2016. https://doi.org/10.21831/jk.v5i2.15147

Sidharta, Y. (2017). Survei Kemampuan Gerak Dasar Lokomotor, Nonlokomotor dan Mnipulatif Siswa Kelas III SD 1 Patokpicis Kecamatan Wajak Kabupaten Malang. Universitas Negeri Malang.

Wijayanti, D. \& Suntado, A. 2017. Upaya Meningkatkan Pemahaman Gerak Dasar Lempar Lembing Melalui Penerapan Lembing Modifikasi Dalam Pembelajaran Atletik. TEGAR: Jurnal of Teaching Physical Education in Elementary School, 1(1), 14-24. https://doi.org/10.17509/tegar.v1i1.8652. 